\section{Simulation of the telepathy experiment with Zener cards}

\section{DOUGLAS M. GAITHER, JR. and LEONARD ZUSNE University of Tulsa, Tulsa, Oklahoma 74104}

The standard parapsychological experiment in telepathy involves the use of a deck of 25 cards, the ESP, or Zener, cards. The deck contains five suits of five symbols: circle, square, cross, star, and wavy lines. The deck is shuffled so that the symbols are arranged in some unsystematic way, the agent (sender) concentrates on one card at a time, and the percipient (receiver) attempts to identify the cards by some nonsensory means (extrasensory perception).

For purposes of researching the factors involved in the card-guessing experiment, it may be necessary to postulate the operation of chance factors alone, that is, that extrasensory perception is not present or does not exist and that sensory information is not available to the receiver. If chance alone is operating, the card-guessing process may be modeled by one series of five digits, each used five times, being compared with another such series, digit pair by digit pair, and the matches being noted. Both series are random. The series that is an analog of the sender's cards is random because randomness is deliberately sought through the process of shuffling the cards; the series that represents the receiver's calls or guesses is also random because the overwhelming majority of actual call series shows no systematicity in the sequencing of symbols. The five digits in the sender's series are equiprobable, each occurring exactly five times. The five digits in the receiver's series may or may not be equiprobable. Some receivers engage in probability guessing, trying to match the exact probability of each symbol, which is generally known. Most individuals, however, generate nonequiprobable series of calls.

Description. The above model was used to write a computer program that simulates the comparison of two random series of digits, or the case where in a cardguessing experiment the null hypothesis cannot be rejected. The two series can be of any length. If there are 25 digits in a series, for instance, one series is kept unchanged and the other is changed 24 times by removing the first digit and making it the last. The changing series is compared with the fixed series in each of the 25 different alignments. Given a number of random series of digits, the program compares all possible pairs of series and, within each pair, as many different alignments as there are items in the series. For instance, 4 series of 25 items each yield the equivalent of 150 runs ( 6 pairings, 25 runs each) or 3,750 trials.
The program has been used to study the effect of length of digit series and deviations from randomness upon the probability density of matches. Results have been obtained from over half-a-million trials.

Input. The program shown in the Appendix was written to process any number of two-dimensional tables (arrays) depending on the requirements of the user. This example processes five. Input data are formatted according to the confines of each table, each column representing a series of digits. Table sizes for this example are: 15 by 25,5 by 75,4 by 125,3 by 175 , 6 by 250 . In addition, a working table dimensioned to accommodate the varying table sizes being considered was created. When the analysis of one table is completed, the working table size adjusts to the size of the next table to be processed.

Output. The output statement, "Total matches in columns $(\mathrm{X})$ and $(\mathrm{Y})$, alignment $(\mathrm{Z})=(\mathrm{N})$ " includes the following information. $X$ equals the column (series), which represents the sender's cards; $Y$ equals the column (series), which represents the receiver's calls; $Z$ equals the specific alignment of the two columns being compared; $\mathrm{N}$ equals the total matches for this alignment. A counter is maintained for alignment and increments on the completion of each matching sequence. A second counter keeps track of the total matches obtained for a given sequence. The total number of alignments is equal to the total number of digits in a column (series).

User Option. The main program is designed to analyze an infinite number of tables. However, organization of input requires changing several statements within the program in order to effect the change. For example, the addition or change of one table requires changes in the dimension statement, read statement loop, write statement loop, adjusting size of working table, and changing label in computed GO statement.

Limitations. Presently, the major limitation is the number of changes required to insert a new table or change an old one. The maximum number of tables considered is dependent only on the limitations of the computer processing it.

Computer and Language. This program is written in FORTRAN IV and has been run on a Xerox Sigma 6 computer.

Time Requirements. This program of five tables required 3.2 CPU min to run and dumped approximately 150 pages of output. CPU time varies according to size and quantity of tables.

Program Availability. A listing of the program and a sample input and output are available at no cost from Leonard Zusne, Psychology Program, University of Tulsa, Tulsa, Oklahoma 74104. 


\section{APPENDIX}

PCL

$\mathrm{PCL}$

C CR TO L1

IMPLICIT INTEGER $(\mathrm{A}=\mathrm{Z})$

DIMENSION T25(15,25),T75(5,75),T125(4,125),T175(3,175),T250(6,250)

1 ,TNN $(1: 15,1: 250)$

$S=0$

TOT $=0$

$X=15$

$\mathrm{Y}=25$

DO $5 \mathrm{~J}=1,25$

$\operatorname{READ}(105,10)(\mathrm{T} 25(\mathrm{I}, \mathrm{J}), \mathrm{I}=1,15)$

10 FORMAT(15I1)

5 CONTINUE

$\operatorname{READ}(105,20),((\mathrm{T} 75(\mathrm{I}, \mathrm{J}), \mathrm{I}=1,5), \mathrm{J}=1,75)$

20 FORMAT(4(15(5I1)/),15(5I1))

DO $25 \mathrm{I}=1,4$

READ $(105,30)(\mathrm{T} 125(\mathrm{I}, \mathrm{J}), \mathrm{J}=1,125)$

30 FORMAT $(7511, /, 5011)$

25 CONTINUE

DO $35 \mathrm{I}=1,3$

READ $(105,40)(\mathrm{T} 175(\mathrm{I}, \mathrm{J}), \mathrm{J}=\mathbf{1}, 175)$

40 FORMAT $(75 \mathrm{I} 1, /, 75 \mathrm{I} 1, /, 25 \mathrm{I} 1)$

35 CONTINUE

DO $45 \mathrm{I}=1,6$

READ $(105,50, \mathrm{END}=88)(\mathrm{T} 250(\mathrm{I}, \mathrm{J}), \mathrm{J}=1,250)$

50 FORMAT(75I $1, /, 75 \mathrm{I} 1, / 75 \mathrm{I} 1, /, 25 \mathrm{I} 1)$

45 CONTINUE

88 DO $6 \mathrm{~J}=1,25$

WRITE $(108,12)(\mathrm{T} 25(\mathrm{I}, \mathrm{J}), \mathrm{I}=1,15)$

12 FORMAT $(1 \mathrm{X}, 15(12,3 \mathrm{X}))$

6 CONTINUE

DO $8 \mathrm{~J}=1,75$

WRITE $(108,14)(\mathrm{T} 75(\mathrm{I}, \mathrm{J}), \mathrm{I}=1,5),(\mathrm{T} 125(\mathrm{I}, \mathrm{J}), \mathrm{I}=1,4),(\mathrm{T} 175(\mathrm{I}, \mathrm{J}), \mathrm{I}=1,3)$

$X,(T 250(I, J), I=1,6)$

14 FORMAT $(1 \mathrm{H} 0,5(12,3 \mathrm{X}), 5 \mathrm{X}, 4(\mathrm{I} 2,3 \mathrm{X}), 5 \mathrm{X}, 3(\mathrm{I} 2,3 \mathrm{X}), 5 \mathrm{X}, 6(\mathrm{I} 2,3 \mathrm{X}))$

8 CONTINUE

DO $11 \mathrm{~J}=76,125$

WRITE $(108,13)(\mathrm{T} 125(\mathrm{I}, \mathrm{J}), \mathrm{I}=1,4),(\mathrm{T} 175(\mathrm{I}, \mathrm{J}), \mathrm{I}=1,3),(\mathrm{T} 250(\mathrm{I}, \mathrm{J}), \mathrm{I}-1,6)$

13 FORMAT(1H0,30X,4(I2,3X),5X,3(12,3X),5X,6(12,3X)

11 CONTINUE

DO $15 \mathrm{~J}=126,175$

WRITE $(108,19)(\mathrm{T} 175(\mathrm{I}, \mathrm{J}), \mathrm{I}=1,3),(\mathrm{T} 250(\mathrm{I}, \mathrm{J}), \mathrm{I}=1,6)$

19 FORMAT $(1 \mathrm{H} 0,55 \mathrm{X}, 3(\mathrm{I} 2,3 \mathrm{X}), 5 \mathrm{X}, 6(12,3 \mathrm{X}))$

15 CONTINUE

DO $21 \mathrm{~J}=176,250$

WRITE $(108,22)(\mathrm{T} 250(\mathrm{I}, \mathrm{J}), \mathrm{I}=1,6)$

22 FORMAT(1H0,75X,6(I2,3X)

21 CONTINUE

DO $3 \mathrm{~J}=1, \mathrm{Y}$

DO $4 \mathrm{I}=1, \mathrm{X}$

TNN $(\mathrm{I}, \mathrm{J})=\mathrm{T} 25(\mathrm{I}, \mathrm{J})$

4 CONTINUE

3 CONTINUE

$\mathrm{I}=1$

$\mathrm{K}=2$

$18 \quad \mathrm{CNT}=\mathrm{Y}$

LINE $=1$

9 DO $55 \mathrm{~J}=1, \mathrm{Y}$

IF(TNN(I,J).EQ.TNN(K,J))TOT=TOT $+1 ;$ GO TO 55

55 CONTINUE

WRITE(108,59)I,K,LINE,TOT

59 FORMAT('TOTAL MATCHES IN COLUMNS ',I2,' AND ',I2,' ALIGNMENT,', $\mathrm{XI} 3{ }^{\prime}=$ ',I2)

LINE $=$ LINE +1

TOT $=0$

$\mathrm{SUB}=\mathrm{TNN}(\mathrm{K}, 1)$

DO $60 \mathrm{~J}=1, \mathrm{Y}-1$ 

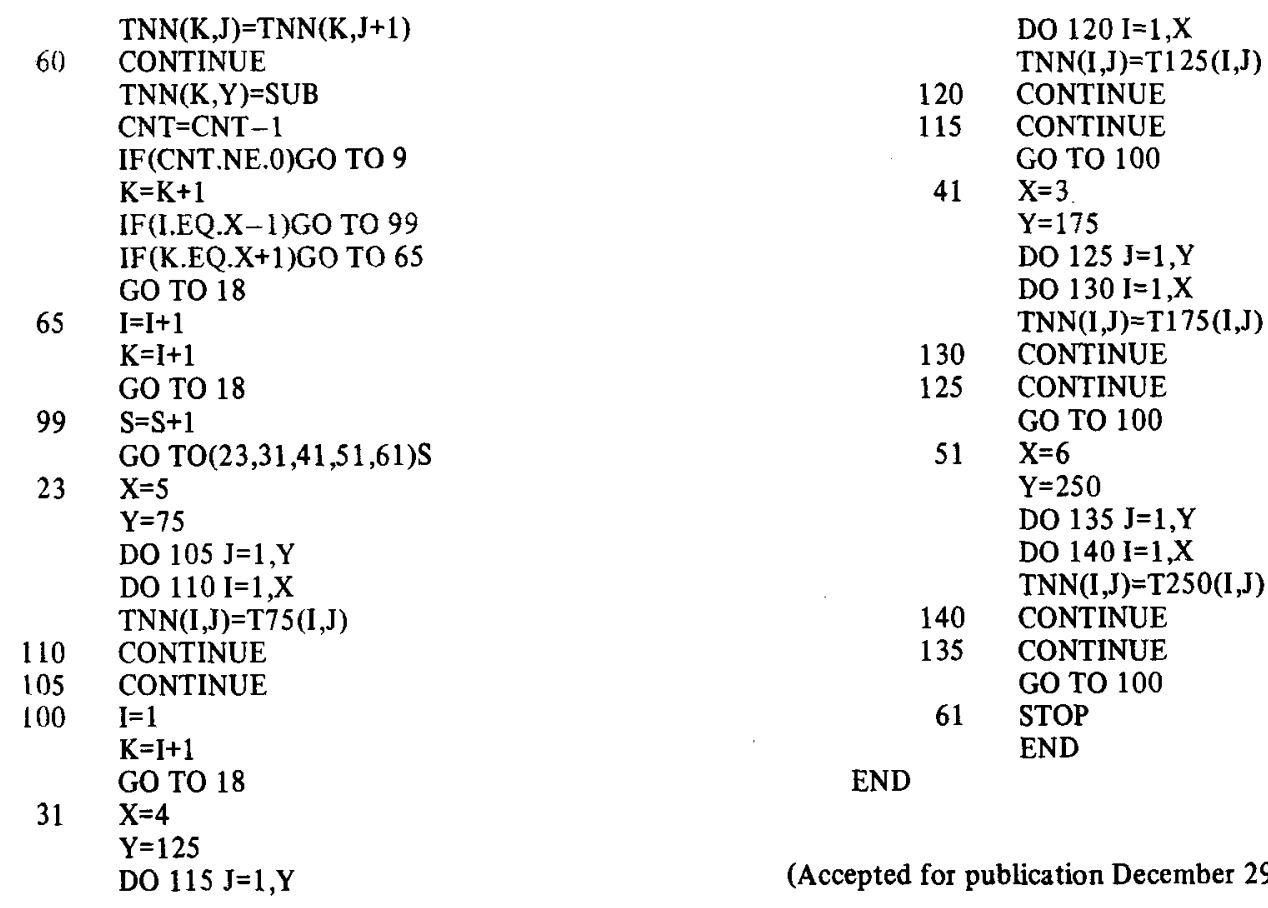

(Accepted for publication December 29, 1977.) 